\title{
Preoperative Thromboelastometry as a Predictor of Transfusion Requirements during Adult Living Donor Liver Transplantation
}

\author{
Nirmeen Fayed $^{\mathrm{a}}$ Wessam Mourad $^{\mathrm{b}}$ Khaled Yassen $^{\mathrm{a}}$ Klaus Görlinger $^{\mathrm{c}, \mathrm{d}}$ \\ a Department of Anesthesia, National Liver Institute, Menoufiya University, Shebeen El Kom City, Egypt; \\ ${ }^{b}$ Department of Public Health, Community Medicine and Statistics, National Liver Institute, Menoufiya University, \\ Shebeen El Kom City, Egypt; \\ ${ }^{c}$ Department of Anesthesiology and Intensive Care Medicine, University Hospital Essen, University Duisburg-Essen, Essen, Germany; \\ dTem International GmbH, Munich, Germany
}

\section{Keywords}

Adult living donor liver transplantation .

Allogeneic blood transfusion - Blood coagulation .

Point-of-care testing $\cdot$ Thromboelastometry

\section{Summary}

Background: The ability to predict transfusion requirements may improve perioperative bleeding management as an integral part of a patient blood management program. Therefore, the aim of our study was to evaluate preoperative thromboelastometry as a predictor of transfusion requirements for adult living donor liver transplant recipients. Methods: The correlation between preoperative thromboelastometry variables in 100 adult living donor liver transplant recipients and intraoperative blood transfusion requirements was examined by univariate and multivariate linear regression analysis. Thresholds of thromboelastometric parameters for prediction of packed red blood cells (PRBCs), fresh frozen plasma (FFP), platelets, and cryoprecipitate transfusion requirements were determined with receiver operating characteristics analysis. The attending anesthetists were blinded to the preoperative thromboelastometric analysis. However, a thromboelastometry-guided transfusion algorithm with predefined trigger values was used intraoperatively. The transfusion triggers in this algorithm did not change during the study period. Results: Univariate analysis confirmed significant correlations between PRBCs, FFP, platelets or cryoprecipitate transfusion re-

Khaled Yassen and Klaus Görlinger contributed equally to this manuscript. quirements and most thromboelastometric variables. Backward stepwise logistic regression indicated that EXTEM coagulation time (CT), maximum clot firmness (MCF) and INTEM CT, clot formation time (CFT) and MCF are independent predictors for PRBC transfusion. EXTEM CT, CFT and FIBTEM MCF are independent predictors for FFP transfusion. Only EXTEM and INTEM MCF were independent predictors of platelet transfusion. EXTEM CFT and MCF, INTEM CT, CFT and MCF as well as FIBTEM MCF are independent predictors for cryoprecipitate transfusion. Thromboelastometry-based regression equation accounted for $63 \%$ of PRBC, $83 \%$ of $\mathrm{FFP}, 61 \%$ of cryoprecipitate, and $44 \%$ of platelet transfusion requirements. Conclusion: Preoperative thromboelastometric analysis is helpful to predict transfusion requirements in adult living donor liver transplant recipients. This may allow for better preparation and less cross-matching prior to surgery. The findings of our study need to be revalidated in a second prospective patient population.

\section{Introduction}

Transfusion practice during liver transplantation varies widely between different centers [1-4]. Notably, many patients with endstage liver disease show normal viscoelastic coagulation profiles despite thrombocytopenia and increased international normalized ratio (INR). This reflects a re-balance of hemostasis in this patient population and explains that some of these patients can undergo 
surgery without blood transfusion. However, this balance is unstable and can quickly decompensate, resulting in bleeding and thrombosis [5-7]. Therefore, the ability to predict intraoperative blood loss and transfusion requirements would be of great help to ensure adequate blood product supply and to enable appropriate therapy for patients at high bleeding risk [8-11]. This would also help anesthetists determining patients who are more likely to benefit from blood-salvaging techniques, prophylactic antifibrinolytic agents, and goal-directed therapy as an integral part of a patient blood management program [12-16]. Furthermore, it may help to reduce the quantity of blood prepared and reserved for patients at low risk of transfusion requirement with subsequent decrease in activity-based costs [17-19]. For all these reasons, several attempts have been made to identify patients at high risk for bleeding and to define preoperative factors which could help identifying them [10, $11,20,21]$.

Blood transfusion during liver transplantation is primarily attributed to the correction of complex derangements of hemostasis and to perioperative hemorrhage. The improvement of surgical and anesthesia management had led to an overall significant reduction in intraoperative blood loss among adult liver transplant recipients [22-23]. However, coagulation and transfusion management in patients undergoing liver transplantation remains to be challenging. Therefore, perioperative monitoring of hemostasis is essential to predict the risk of bleeding during invasive interventions and surgery, to detect potential causes of hemorrhage timely, and to guide hemostatic therapy [16, 23-25].

The value of the most commonly used routine laboratory coagulation tests (prothrombin time (PT), activated partial thromboplastin time (aPTT), and platelet count) is questionable in the acute perioperative setting due to their long turnaround time and their inability to adequately reflect the complex changes in hemostasis in patients with liver cirrhosis [6, 26-33]. Thromboelastometry offers rapid, comprehensive, and global clinical assessment of the patients' coagulation status, as demonstrated by several studies [33-39]. In contrast to standard coagulation tests, thromboelastometric analysis provides information about the coagulation initiation, mechanical clot stability, and fibrinolysis. Thromboelastometric analysis includes plasmatic coagulation and fibrinolytic factors and inhibitors as well as circulating blood cells, reflecting most parts of the cellbased model of hemostasis [40] and providing clinically important information about the quality of the final blood clot [20, 23, 41-45]. In contrast, standard coagulation tests such as PT and aPTT reflect the plasmatic activity of clotting factors according to the extrinsic and intrinsic pathway of the cascade model, solely [5-7, 28, 31].

This study aims to assess preoperative ROTEM parameters as predictors for blood transfusion requirements in recipients of adult living donor liver transplant (ALDLT).

\section{Material and Methods}

After approval of ethical committee of Liver Institute Menoufiya University, Egypt (Chairman: Professor Hossam Abd-Elatif, MD 16/2011) and written informed consent, this prospective observational study was carried out on 100 consecutive recipients of ALDLT which were managed by the same surgical and anesthetic teams. Cases with severe surgical bleeding due to vascular injury were excluded.

\section{Thromboelastometry}

Principles of thromboelastometry (ROTEM delta; Tem International GmbH, Munich, Germany) were described elsewhere [46-51]. Thromboelastometry has already widely been used to monitor coagulation changes and to guide coagulation therapy in trauma patients [35-37, 43-45, 52-54], during liver transplantation $[4,16,23,25,38,41-45,47,55,56]$, and during cardiac surgery $[24,25,39,43-45,57-61]$.

In this study, preoperative thromboelastometric analyses were done for all patients and quality controls using ROTROL N (modified human plasma with normal clotting time (CT) and maximum clot firmness (MCF)) and P (modified human plasma with pathologic CT and MCF) (alternatively used on every second day) as well as EXTEM and INTEM (used on two channels, each) were performed on each day the system was used. EXTEM, FIBTEM, and INTEM tests (Tem International $\mathrm{GmbH}$ ) were analyzed simultaneously. The EXTEM assay uses extrinsic activation by recombinant tissue factor. The FIBTEM assay, in addition to tissue factor, includes cytochalasin D, which blocks the platelet function. Therefore, MCF in FIBTEM reflects the firmness of the fibrin clot only and can be used in combination with EXTEM to differentiate between fibrinogen deficiency / fibrin polymerization disorders and thrombocytopenia / severe platelet dysfunction. In contrast, the INTEM assay uses intrinsic activation by ellagic acid. $5 \mathrm{ml}$ citrated whole blood samples $(0.109 \mathrm{~mol} / \mathrm{l}$ of citrate; 9NC; Becton, Dickinson and Co., Franklin Lakes, NJ, USA) were taken from the arterial line and mixed immediately. Thromboelastometric analyses were performed within $10 \mathrm{~min}$ after blood sampling at $37^{\circ} \mathrm{C}$ after anew gentle mixing of the blood sample. Blood samples for thromboelastometry were taken preoperatively and once in each phase of liver transplantation (pre-anhepatic, anhepatic, after reperfusion, and at the end of surgery) as well as in case of clinical evidence of bleeding. The thromboelastometric parameters measured included coagulation time (CT, in seconds), the time from the start of measurement until a clot firmness of $2 \mathrm{~mm}$ was detected; clot formation time (CFT, in seconds), the time needed to increase clot firmness from 2 to $20 \mathrm{~mm}$ amplitude; angle $\alpha$, the angle of tangent at $2 \mathrm{~mm}$ amplitude (ANG $\alpha$, in degrees); and maximum clot firmness (MCF, in millimeters), the maximum amplitude of clot firmness finally achieved. All perioperative analyses were done by one anesthetist who was not involved in the management of the recipients. The anesthetists managing the patients were blinded to the preoperative thromboelastometric analysis, but not to the intraoperative thromboelastometric analyses which have been used for intraoperative decision-making according to a thromboelastometryguided transfusion algorithm (fig. 1). The transfusion triggers in this algorithm did not change during the study period.

Conventional Coagulation Tests

aPTT, PT, INR, and plasma fibrinogen concentration (Clauss method) were measured semi-automatically in citrated platelet-poor plasma using Fibrintimer (Siemens-Dade Behring Healthcare Diagnostics, Marburg, Germany). Platelet count, hemoglobin concentration, and hematocrit (HCT) were measured in EDTA blood with a Coulter Counter (Beckman Coulter Diagnostics, Brea, CA, USA).

\section{Anesthesia Management}

No premedication was administered. After standard monitoring was in place, anesthesia was induced with propofol $2 \mathrm{mg} / \mathrm{kg}$ and fentanyl $1.5 \mu \mathrm{g} / \mathrm{kg}$, and rocuronium $0.9 \mathrm{mg} / \mathrm{kg}$ was given to facilitate rapid sequence orotracheal intubation with a cuffed tube. Anesthesia was maintained with sevoflurane in $\mathrm{O}_{2}$ : air mixture $\left(\mathrm{FiO}_{2}=0.4\right)$ and fentanyl to keep Spectral Entropy (GE Healthcare, Helsinki, Finland) between $40 \%$ and $60 \%$. Normothermia was achieved with a forced-air warming device (Bair Hugger Temperature Management Unit, Model 750; Arizant Healthcare Inc., Eden Prairie, MN, USA), and mechanical ventilation was adjusted to keep normoxia and normocapnia. Transesophageal Doppler (EDM; Deltex Medical Ltd, Chichester, West Sussex, UK) was passed nasally into the mid-esophagus until aortic blood flow signals 


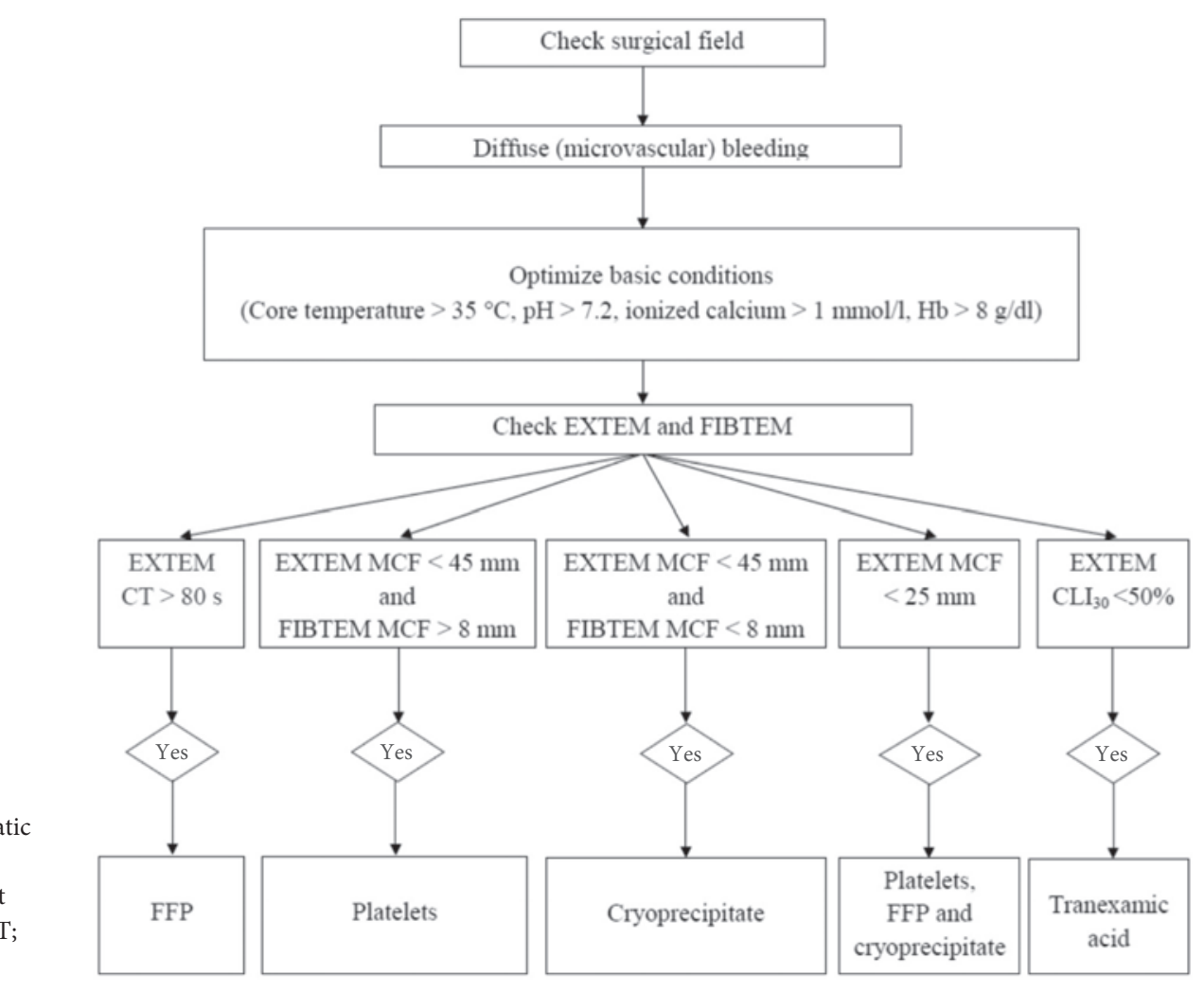

Fig. 1. Thromboelastometry-guided hemostatic algorithm.

$\mathrm{CLI}_{30}=$ Clot lysis index defined as residual clot firmness in percentage of MCF $30 \mathrm{~min}$ after CT; $\mathrm{HB}=$ hemoglobin.

were identified to measure the corrected flow time and stroke volume which was used for guiding volume therapy during the procedure. Serum electrolytes and $\mathrm{pH}$ were monitored hourly. Intraoperative blood transfusion followed a thromoelastometry-based protocol presented in figure 1 [47]. Fresh frozen plasma (FFP) was given in a dose of $10 \mathrm{~m} / \mathrm{kg}$, cryoprecipitate in a dose of 1 unit / $10 \mathrm{~kg}$ body weight, and platelets in a dose of 6 single donor units when indicated. HCT was always kept above $24 \%$ by giving packed red blood cells (PRBCs). Tranexamic acid was given in a dose of $10 \mathrm{mg} / \mathrm{kg}$ if there was evidence of hyperfibrinolysis by thromboelastometry.

\section{Calculation of Intraoperative Blood Loss}

Intraoperative blood loss was calculated using a modification of the Gross formula [62] given below, in addition to the quantity of transfused red blood cells.

$\mathrm{BL}=\mathrm{BV}(\mathrm{HCT}(\mathrm{i})-\mathrm{HCT}(\mathrm{f})) / \mathrm{HCT}(\mathrm{m})$

where $\mathrm{BL}$ was the blood loss and $\mathrm{BV}$ was the blood volume calculated from the body weight (blood volume in $\mathrm{ml}=$ body weight in $\mathrm{kg} \times 70 \mathrm{ml} / \mathrm{kg}$ ). HCT (i), HCT (f) and HCT (m) were the initial, final and mean (of the initial and final) hematocrit, respectively.

\section{Measurements}

Preoperative thromboelastometric parameters of EXTEM, FIBTEM, and INTEM, intraoperative allogeneic blood transfusion requirements (PRBCs, FFP, platelets, and cryoprecipitate) in units, calculated blood loss in milliliters, preoperative INR, platelet count, hemoglobin and fibrinogen levels, operation time in hours, and intravenous fluids infused in liters during the procedure were documented.

\section{Statistics}

100 patients with thromboelastometric analysis during liver transplantation were recruited due to sample size and power calculation based on the following assumptions: power of $85 \%$, a error $=0.05$, and the proportion of thromboelastometric analysis used in liver transplantation is $72.6 \%$. The required sample size was determined using Epi Info Software.
Data were statistically analyzed using SPSS for Windows, version 17 , and for all analyses a $\mathrm{p}$ value $<0.05$ was considered statistically significant. Data were shown as mean, range and frequency, as appropriate. Receiver operating characteristics (ROC) curve analyses were performed to determine the optimal cutoff levels with the highest sensitivity and specificity for all variables tested. Multivariate logistic regression analysis was performed on factors identified as significantly different in a univariate analysis between patients in order to determine adjusted odds ratio (OR) and $95 \%$ confidence interval $(95 \% \mathrm{CI})$ to detect the factors that are independently associated.

\section{Results}

Preoperative thromboelastometric measurements were performed in 110 patients between April 2011 and September 2012. Three cases were cancelled due to the growth of the hepatic tumor beyond surgical excision, and further 7 recipients were excluded: 2 due to vascular injury with severe surgical bleeding and 5 because of blood transfusion protocol violation as the blood product transfusion was not guided by thromboelastometric parameters.

100 patients were successfully included in the study. 71 patients suffered from hepatitis $\mathrm{C}$, while 29 had hepatocellular carcinoma on top of hepatitis $C$. The mean $( \pm$ SD) age was $47.3 \pm 6.6$ years and model of end-stage liver disease (MELD) score was $16.27 \pm$ 3.17. The mean operation time was $10.08 \pm 2.31 \mathrm{~h}$. The mean graft volume/recipient body weight ratio was $1.08 \pm 0.2$. The mean amount of Ringer's acetate and hydroxyethyl starch solution transfused was $5.11 \pm 0.34 \mathrm{l}$ and $2.03 \pm 0.44 \mathrm{l}$, respectively. Tranexamic acid was administered in 7 patients. 
Table 1. Descriptive statistics of preoperative conventional coagulation tests, ROTEM parameters, transfusion requirements, and blood loss

\begin{tabular}{lllll}
\hline & Mean & SD & Minimum & Maximum \\
\hline aPTT, s & 47.5 & 14.2 & 22 & 94 \\
INR & 1.67 & 0.43 & 1.1 & 3.0 \\
Platelet count, mm ${ }^{-3}$ & 70.14 & 29.23 & 23 & 150 \\
HB, g/dl & 11.13 & 1.32 & 8.5 & 14 \\
HCT, \% & 32.5 & 4.1 & 24 & 44 \\
Fibrinogen, mg/dl & 124.94 & 53.28 & 33 & 300 \\
EXTEM CT, s & 89.08 & 43.9 & 33 & 227 \\
EXTEM CFT, s & 292.04 & 140.01 & 92 & 794 \\
EXTEM MCF, mm & 42.81 & 9.05 & 27 & 68 \\
EXTEM ANG $\alpha$, degree & 49.09 & 12.9 & 28 & 78 \\
INTEM CT, s & 178.18 & 48.24 & 100 & 331 \\
INTEM CFT, s & 246.4 & 105.7 & 82 & 562 \\
INTEM MCF, mm & 43.37 & 7.84 & 28 & 63 \\
INTEM ANG $\alpha$, degree & 49.92 & 13.18 & 24 & 78 \\
FIBTEM MCF, mm & 9.24 & 2.85 & 4 & 16 \\
Blood loss, ml & 3,270 & $1,085.7$ & 1,500 & 6,000 \\
PRBCs, units & 4.24 & 3.5 & 0.00 & 14 \\
FFP, units & 4.62 & 4.47 & 0.00 & 18 \\
Platelets, units & 1.8 & 1.15 & 0.00 & 24 \\
Cryoprecipitate, units & 3.6 & 2.34 & 0.00 & 22 \\
\hline
\end{tabular}

Table 2. Backward stepwise logistic regression model (multivariate analysis) of all studied variables associated with packed red blood cell transfusion

\begin{tabular}{llllll}
\hline Studied variables & \multicolumn{5}{l}{ PRBC transfusion } \\
\cline { 2 - 6 } & B & SE & P & OR & $95 \%$ CI \\
\hline B0 & & \multicolumn{5}{c}{27.58} \\
EXTEM (CT) & 0.132 & 0.057 & $<0.05$ & 1.141 & $1.021-1.275$ \\
EXTEM (MCF) & -0.532 & 0.063 & $<0.05$ & 0.877 & $0.775-0.991$ \\
INTEM (CT) & 0.053 & 0.025 & $<0.05$ & 0.948 & $0.903-0.996$ \\
INTEM (CFT) & 0.021 & 0.010 & $<0.05$ & 0.979 & $0.960-0.998$ \\
INTEM (MCF) & -0.512 & 0.179 & $<0.01$ & 0.599 & $0.422-0.851$ \\
FIBTEM (MCF) & -0.621 & 0.011 & $<0.05$ & 1.022 & $1.000-1.043$ \\
\hline
\end{tabular}

Variables entered on step 1: EXTEM CT, EXTEM CFT, EXTEM MCF, EXTEM Ang $\alpha$, INTEM CT, INTEM CFT, INTEM MCF, INTEM Ang $\alpha$, FIBTEM MCF.

The regression equation for PRBCs transfusion $=27.58+0.132 \times$ EXTEM (CT) $-0.532 \times$ EXTEM (MCF) $+0.053 \times$ INTEM $(C T)+0.021 \times$ INTEM (CFT) $-0.512 \times$ INTEM (MCF) $-0.621 \times$ FIBTEM (MCF).

The correlation coefficient $\mathrm{R}^{2}$ for the final regression equation $=0.63$.

Results of preoperative conventional coagulation tests, preoperative thromboelastometric parameters, blood loss, and transfusion requirements are presented in table $1.19 \%$ of the recipients did not receive any blood products, $22 \%$ did not receive PRBCs, $38 \%$ did not receive FFPs, $88 \%$ did not receive platelets, and $64 \%$ did not receive cryoprecipitate.

Univariate analysis confirmed significant associations between PRBC transfusion and thromboelastometric variables studied. Stepwise backward multivariate analysis assigned EXTEM CT and MCF as well as INTEM CT, CFT and MCF as independent predictors of PRBC transfusion and FIBTEM MCF as a dependent predictor of $\mathrm{PRBC}$ transfusion. Data and regression equation for $\mathrm{PRBC}$ transfusion are presented in table 2.
Table 3. Backward stepwise logistic regression model (multivariate analysis) of all studied variables associated with fresh frozen plasma transfusion

\begin{tabular}{llllll}
\hline Studied variables & \multicolumn{6}{l}{ FFP transfusion } \\
\cline { 2 - 6 } & $\mathrm{B}$ & $\mathrm{SE}$ & $\mathrm{P}$ & $\mathrm{OR}$ & $95 \% \mathrm{CI}$ \\
\hline$\beta 0$ & & \multicolumn{5}{c}{13.57} \\
EXTEM CT & 0.045 & 0.021 & $<0.05$ & 0.956 & $0.917-0.997$ \\
EXTEM CFT & 0.041 & 0.019 & $<0.05$ & 1.042 & $1.004-1.081$ \\
EXTEM ANG $\alpha$ & -0.299 & 0.254 & $>0.05$ & 1.491 & $0.907-2.452$ \\
INTEM CT & 0.048 & 0.025 & $>0.05$ & 1.049 & $0.999-1.103$ \\
INTEM CFT & 0.057 & 0.016 & $>0.05$ & 0.973 & $0.944-1.004$ \\
INTEM MCF & -0.230 & 0.132 & $>0.05$ & 0.794 & $0.613-1.029$ \\
INTEM ANG $\alpha$ & -0.297 & 0.238 & $>0.05$ & 0.673 & $0.422-1.071$ \\
FIBTEM MCF & -0.943 & 0.526 & $<0.05$ & 0.319 & $0.114-0.894$ \\
\hline
\end{tabular}

Variables entered on step 1: EXTEM CT, EXTEM CFT, EXTEM MCF, EXTEM ANG $\alpha$, INTEM CT, INTEM CFT, INTEM MCF, INTEM ANG $\alpha$, FIBTEM MCF.

The regression equation for FFP transfusion $=13.57+0.045 \times$ EXTEM $(C T)$ $+0.041 \times$ EXTEM $($ CFT $)-0.943 \times$ FIBTEM $($ MCF $)-0.299 \times$ EXTEM $(\mathrm{ANG} \alpha)+0.048 \times$ INTEM CT $+0.057 \times$ INTEM $($ CFT $)-0.23 \times$ INTEM (MCF) $-0.297 \times$ INTEM $($ ANG $\alpha)$.

The correlation coefficient $\mathrm{R}^{2}$ for the final regression equation $=0.83$.

Table 4. Backward stepwise logistic regression model (multivariate analysis) of all studied variables associated with platelet transfusion

\begin{tabular}{llllll}
\hline Studied variables & \multicolumn{5}{l}{ Platelet transfusion } \\
\cline { 2 - 6 } & $\mathrm{B}$ & $\mathrm{SE}$ & $\mathrm{P}$ & $\mathrm{OR}$ & $95 \% \mathrm{CI}$ \\
\hline BO & & \multicolumn{5}{c}{9.96} \\
EXTEM MCF & -0.106 & 0.181 & 0.025 & 1.500 & $1.053-2.137$ \\
INTEM MCF & -0.104 & 0.245 & 0.004 & 0.495 & $0.306-0.799$ \\
\hline
\end{tabular}

Variables entered on step 1: EXTEM CFT, EXTEM MCF, EXTEM ANG $\alpha$, INTEM MCF, INTEM ANG $\alpha$, FIBTEM MCF.

The regression equation for platelet transfusion $=9.96-0.106 \times$ EXTEM (MCF) $-0.104 \times$ INTEM (MCF).

The correlation coefficient $\mathrm{R}^{2}$ for the final regression equation $=0.44$.

Table 5. Backward stepwise logistic regression model (multivariate analysis) of all studied variables associated with cryoprecipitate transfusion

\begin{tabular}{lrlllll}
\hline \multirow{2}{*}{ Studied variables } & \multicolumn{7}{c}{ Cryoprecipitate transfusion } \\
\cline { 2 - 7 } & $\mathrm{B}$ & $\mathrm{SE}$ & $\mathrm{P}$ & $\mathrm{OR}$ & $95 \% \mathrm{CI}$ \\
\hline B0 & & \multicolumn{7}{c}{28.13} \\
FIBTEM MCF & -1.502 & 0.009 & 0.001 & 0.572 & 0.955 & 0.989 \\
EXTEM CFT & 0.018 & 0.007 & 0.016 & 1.018 & 1.003 & 1.033 \\
EXTEM MCF & -0.307 & 0.066 & 0.006 & 0.863 & 0.759 & 0.982 \\
INTEM CT & 0.019 & 0.009 & 0.026 & 0.981 & 0.965 & 0.998 \\
INTEM CFT & 0.025 & 0.011 & 0.002 & 0.966 & 0.945 & 0.987 \\
INTEM MCF & -0.302 & 0.088 & 0.002 & 0.754 & 0.434 & 0.897 \\
\hline
\end{tabular}

Variables entered on step 1: EXTEM CT, EXTEM CFT, EXTEM MCF, EXTEM ANG $\alpha$, INTEM CT, INTEM CFT, INTEM MCF, INTEM ANG $\alpha$, FIBTEM MCF.

The regression equation of cryoprecipitate transfusion $=28.13+0.018 \times$ EXTEM $($ CFT $)-0.307 \times$ EXTEM $(\mathrm{MCF})+0.025 \times$ INTEM $($ CFT $)+0.019 \times$ INTEM (CT) $-0.302 \times$ INTEM (MCF) $-1.502 \times$ FIBTEM (MCF).

The correlation coefficient $\mathrm{R}^{2}$ for the final regression equation $=0.61$. 
Table 6. The cut-off values of independent ROTEM variables with their sensitivity and specificity that at best predicted the transfusion threshold for (PRBCs, FFP, cryoprecipitate, and platelets

\begin{tabular}{|c|c|c|c|c|c|c|c|c|c|c|}
\hline ROTEM variable & Cut-off value & Sensitivity, \% & Specificity, \% & AUC & Accuracy, \% & PPV, \% & NPV, \% & $\mathrm{p}$ value & SE & $\mathrm{CI}$ \\
\hline \multicolumn{11}{|l|}{ PRBCs } \\
\hline EXTEM CT, s & 62 & 79.5 & 63.6 & 0.76 & 76.8 & 46.4 & 20.5 & $<0.01$ & 0.05 & $0.66-0.86$ \\
\hline INTEM CT, s & 155 & 79.5 & 54.5 & 0.75 & 75.3 & 45.5 & 20.5 & $<0.01$ & 0.05 & $0.65-0.86$ \\
\hline INTEM CFT, s & 205.5 & 71.8 & 72.7 & 0.75 & 75.4 & 27.3 & 28.2 & $<0.01$ & 0.06 & $0.64-0.87$ \\
\hline EXTEM MCF, mm & 44 & 100 & 70.5 & 0.87 & 87.4 & 29.5 & 0.0 & $<0.01$ & 0.03 & $0.81-0.94$ \\
\hline INTEM MCF, mm & 44.5 & 100 & 71.8 & 0.88 & 88.0 & 28.2 & 0.0 & $<0.01$ & 0.03 & $0.81-0.95$ \\
\hline \multicolumn{11}{|l|}{ FFP } \\
\hline EXTEM CT, s & 67 & 77.4 & 57.9 & 0.73 & 73.2 & 42.1 & 22.6 & $<0.01$ & 0.05 & $0.63-0.84$ \\
\hline EXTEM CFT, s & 223 & 83.9 & 78.9 & 0.90 & 90.7 & 21.1 & 16.1 & $<0.01$ & 0.03 & $0.85-0.96$ \\
\hline FIBTEM MCF, mm & 9.5 & 84.2 & 74.2 & 0.81 & 81.6 & 25.8 & 15.8 & $<0.01$ & 0.04 & $0.73-0.89$ \\
\hline \multicolumn{11}{|l|}{ Cryoprecipitate } \\
\hline INTEM CT, s & 178.5 & 77.8 & 65.6 & 0.68 & 67.5 & 34.4 & 22.2 & $<0.01$ & 0.05 & $0.57-0.78$ \\
\hline EXTEM CFT, s & 238.5 & 77.8 & 56.2 & 0.74 & 74.7 & 43.8 & 22.2 & $<0.01$ & 0.04 & $0.65-0.84$ \\
\hline INTEM CFT, s & 205.5 & 77.8 & 46.9 & 0.72 & 71.7 & 53.1 & 22.2 & $<0.01$ & 0.05 & $0.62-0.82$ \\
\hline EXTEM MCF, mm & 36.5 & 90.6 & 52.8 & 0.78 & 78.2 & 47.2 & 9.4 & $<0.01$ & 0.05 & $0.69-0.87$ \\
\hline INTEM MCF, mm & 38.5 & 87.5 & 63.9 & 0.80 & 80.3 & 36.1 & 12.5 & $<0.01$ & 0.05 & $0.71-0.89$ \\
\hline FIBTEM MCF, mm & 8.5 & 81.3 & 83.3 & 0.84 & 85.3 & 16.7 & 18.7 & $<0.01$ & 0.04 & $0.76-0.92$ \\
\hline \multicolumn{11}{|l|}{ Platelets } \\
\hline EXTEM MCF, mm & 37.5 & 73.9 & 73.3 & 0.73 & 73.4 & 66.7 & 26.1 & $<0.05$ & 0.06 & $0.61-0.85$ \\
\hline INTEM MCF, mm & 39.5 & 73.9 & 83.3 & 0.82 & 82.3 & 16.7 & 26.1 & $<0.01$ & 0.05 & $0.73-0.92$ \\
\hline
\end{tabular}

The study also found a highly significant association between FFP transfusion and thromboelastometric parameters. Backward stepwise logistic regression model of all studied variables associated with plasma transfusion indicated EXTEM CT and CFT as well as FIBTEM MCF as independent predictors for FFP transfusion while EXTEM angle $\alpha$ and INTEM variables were dependent predictors of FFP transfusion. Data and regression equation for FFP transfusion are presented in table 3 .

Platelet transfusion was associated with EXTEM CFT, MCF and angle $\alpha$, with INTEM MCF and angle $\alpha$ ) as well as with FIBTEM MCF. Multivariate analysis of all studied variables associated with platelets transfusion indicated that only EXTEM and INTEM MCF were independent predictors of platelet transfusion. Data and regression equation for platelet transfusion are presented in table 4 .

Finally the univariate analysis confirmed the association between cryoprecipitate transfusion and other thromboelastometric parameters. The backward stepwise logistic regression model showed that EXTEM CFT and MCF, INTEM CT, CFT and MCF as well as FIBTEM MCF were independent predictors for cryoprecipitate transfusion. Data and regression equation for cryoprecipitate transfusion are presented in table 5 .

The cut-off values of independent thromboelastometric variables with the sensitivity and specificity that best predicted the transfusion threshold for PRBCs, FFP, cryoprecipitate, and platelets are shown in table 6. Exemplary ROC curves for prediction of transfusion of PRBCs, FFP, platelets and cryoprecipitate are presented in figure 2.

\section{Discussion}

This study demonstrated that specific preoperative thromboelastometric parameters were able to predict allogeneic blood transfusion requirements in patients undergoing ALDLT and that incorporating these parameters in a mathematical equation allowed for calculation of intraoperative transfusion requirements.

Several previous attempts to predict blood transfusion requirements by other researchers were explored by using conventional coagulation tests, such as PT, INR and aPTT, and viscoelastic tests such as thromboelastography/thromboelastometry. However, to our best knowledge the thromboelastometric parameters were not incorporated previously into predictive equations that could be used clinically.

The idea behind using preoperative thromboelastometric results to predict transfusion requirement during liver transplantation is that this whole blood test can reflect global hemostasis in contrast to plasmatic conventional coagulation tests. Caldwell et al. $[63,64]$ concluded that in liver disease assessment of coagulation using conventional coagulation tests does not represent the whole coagulation process and the use of global functional tools such as thromboelastometry should be considered. Furthermore, Haas et al. [33] concluded that PT and aPTT cannot be used interchangeably with thromboelastometric CT, and thresholds for transfusion based on PT and aPTT might overestimate the need for coagulation therapy. Poor correlation between mild-to-moderate conventional coagulation tests abnormalities and peri-procedural bleeding 


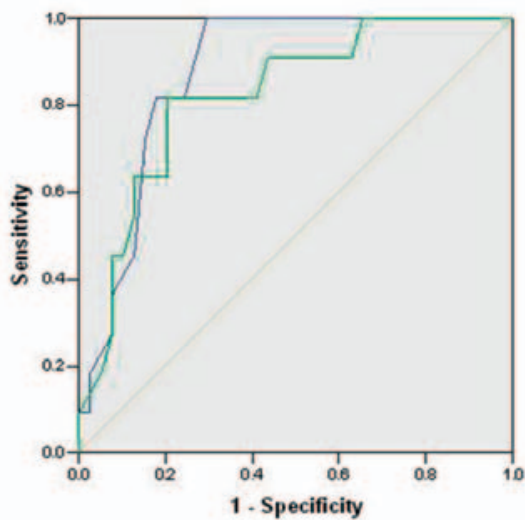

\section{Source of the curve EXTEM MCF EXTEM alpha Reference line}

\section{C} ROC curve platelet transfusion
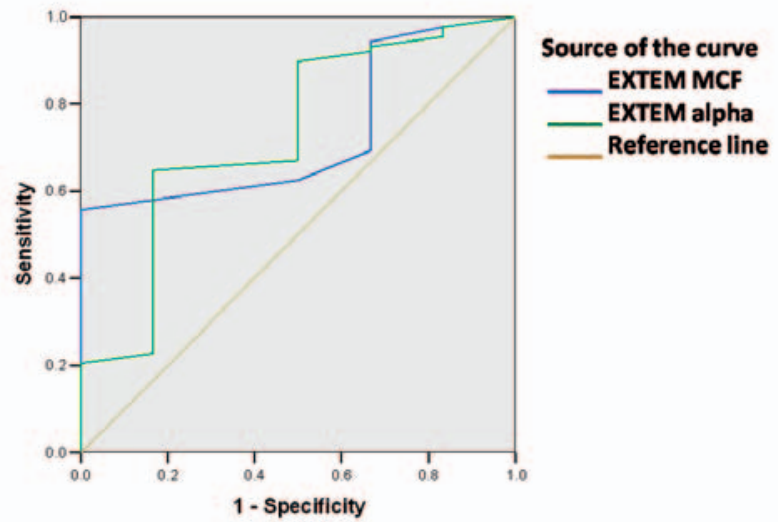
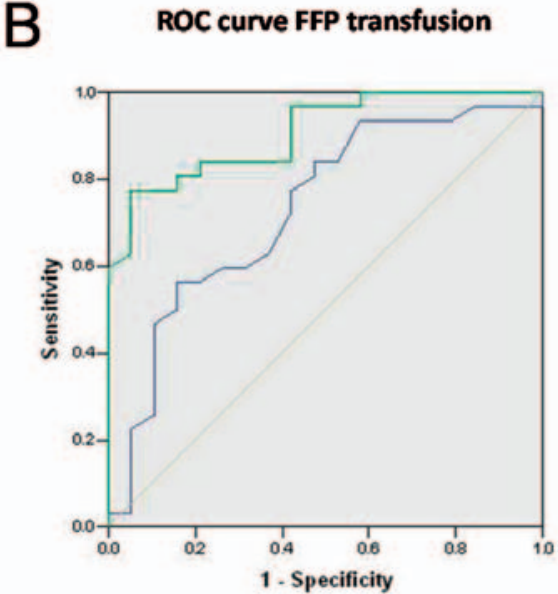

Source of the curve EXTEM CT EXTEM CFT Reference line

\section{ROC Curve cryoprecipitate transfusion}

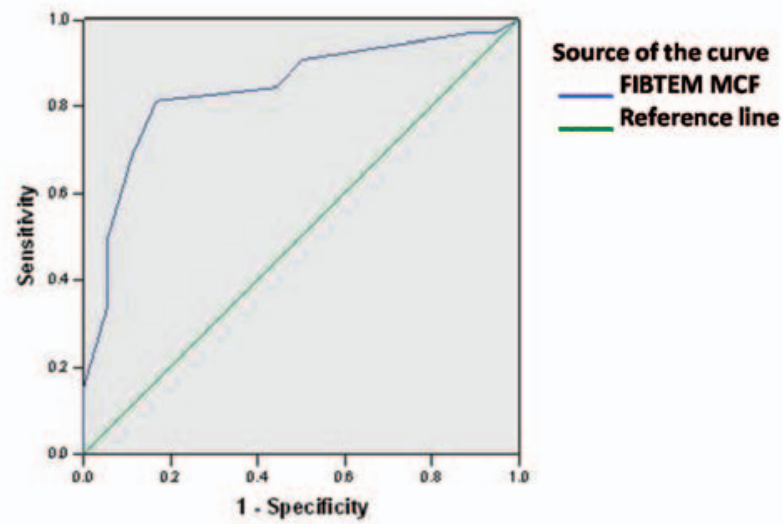

Fig. 2. Exemplary ROC curves for thromboelastometric parameters to predict (A) PRBC, (B) FFP, (C) platelet, and (D) cryoprecipitate transfusion. Corresponding data are presented in table 6 .

or need for PRBC transfusion has been reported for a variety of invasive procedures, such as central venous catheter placement [65-67] and liver biopsy [26, 68], and was recently confirmed in a meta-analysis by Segal and colleagues [69]. Notably, both $\mathrm{Ng}$ et al. [70] and Eckman et al. [71] have shown similar findings in patients undergoing surgical procedures including liver resection. Furthermore, Reyle-Hahn et al. [72] and Massicotte et al. [29] confirmed that preoperative coagulation defects as assessed by conventional coagulation tests are not helpful to guide intraoperative transfusion of blood components or even predict blood transfusion requirements during liver transplantation.

In this study, the thromboelastometry-based models to predict transfusion requirements could predict $83 \%$ of FFP, $63 \%$ of PRBC, $61 \%$ of cryoprecipitate, and $44 \%$ of platelet transfusion cases during liver transplantation. To our best knowledge, thromboelastometry was not used to predict transfusion requirement during liver transplantation, rather it has been evaluated to predict bleeding and transfusion requirements in trauma and cardiac surgery. Ronald et al. [73] analyzed the ability of thromboelastography to predict blood product requirements in cardiac surgery, including 14 studies representing the best evidence on the topic. The authors came to the conclusion that thromboelastography might be useful in predicting patients who are likely to bleed postoperatively.

In contrast, Davidson et al. [74] and Cammerer et al. [75] found that while thromboelastometric parameters are good negative predictors for transfusion requirement, they could not predict excessive postoperative bleeding and transfusion requirement after cardiac surgery. However, these two studies were different compared to our study regarding several baseline characteristics. First, the amount of blood loss was much lower in these studies. In the study by Davidson et al. [74], the blood loss in non-bleeding patients was $150 \mathrm{ml}(25-350 \mathrm{ml})$ and in bleeding patients $787 \mathrm{ml}(250-1,000$ $\mathrm{ml}$ ) while Cammerer et al. [75] reported a total 6-hour blood loss of $536 \pm 296 \mathrm{ml}$. In contrast, we recorded a blood loss of 3,270 ml $(1,500-6,000 \mathrm{ml})$ in the current study. Minimal blood loss might limit the ability of thromboelastometry to predict transfusion requirement. This was in line with the results of a cardiac surgery study published by Lee et al. [76].

Secondly, the study of Davidson et al. [74] was not adequately powered to confirm its poor positive predictive value in the early postoperative period due to small numbers of patients who bleed excessively. In this study only 1 patient received blood products 
other than red blood cells during the study period which makes it difficult to draw any conclusions. In our current study, $78 \%$ of the study population received PRBCs, $62 \% \mathrm{FFP}, 36 \%$ cryoprecipitate, and $12 \%$ platelets. The influence of the number of patients receiving blood products on the predictive value of thromboelastometry was reflected by the correlation coefficient $\mathrm{r}^{2}$ of the regression equation for platelet transfusion which was the lowest. Finally, the preoperative hemostasis in our patients undergoing ALDLT was different compared to the cardiac surgical patients in the study of Davidson et al. [74]. The latter study was evaluating the incidence of postoperative bleeding in initially non-coagulopathic patients. In this clinical setting, coagulopathy develops during surgery and cardiopulmonary bypass itself. Therefore, intraoperatively acquired coagulopathy, rather than preexisting disturbances, may be the main causes of bleeding in cardiac surgery [77]. This may contribute to the poor ability of preoperative thromboelastometric analysis to predict the incidence of bleeding and transfusion requirements in cardiac surgery. This assumption is supported by Cammerer et al. [75] who found that there are significant differences in several thromboelastometric parameters between those patients who have bled excessively in the $2 \mathrm{nd}$ and $3 \mathrm{rd}$ postoperative hour and those who did not. In contrast, our patients were initially coagulopathic and were exposed to further hemostatic derangement intraoperatively. Therefore, preoperative thromboelastometric analysis in patients undergoing liver transplantation showed a better positive predictive value for allogeneic blood transfusion requirements compared to studies in cardiac surgery.

Cammerer et al. [75] also explained the low predictive value of preoperative thromboelastometric analysis for postoperative bleeding and blood loss after cardiac surgery with the multifactorial genesis of blood loss, including surgical reasons. Cammerer et al. [75] and Davidson et al. [74] did not exclude surgical reasons for bleeding. Therefore, a positive predictive value as large as the negative predictive value cannot be expected. Exclusion of cases with severe surgical hemorrhage due to vascular injury may have improved the ability of thromboelastometry to predict intraoperative bleeding in our study.

On the other hand, studies on both penetrating and blunt trauma patients assigned different thromboelastometric variables as predictors for transfusion requirements. It has been found that thromboelastography was a more accurate indicator of blood product requirements than conventional coagulation tests, reduction in clot formation rate and strength were indicative of transfusion requirements in patients with penetrating trauma, and reduced maximum amplitude of the thromboelastographic trace was associated with more blood products transfused [78]. Jeger et al. [79] found that thromboelastographic angle $\alpha$ may be a sensitive predictor of transfusion in moderately injured blunt trauma patients.

For prediction of massive transfusion ( $\geq 10$ units PRBCs transfused within $24 \mathrm{~h}$ after admission), Schöchl et al. [36] demonstrated that FIBTEM MCF and amplitude of clot firmness $10 \mathrm{~min}$ after CT (A10) provide early prediction of massive transfusion in trauma patients. Furthermore, Leemann et al. [80] found elongated CFT and reduced MCF useful to predict the need for massive transfusion reliably, too.
In our study, MCF was an independent predictor for PRBC transfusion, and the cut-off value of $44 \mathrm{~mm}$ provided a sensitivity and specificity of $100 \%$ and $71 \%$, respectively, with an AUC of 0.88 . Other authors confirmed these results, as the ROC area under the curve (AUC) for INTEM MCF reported by Leemann et al. [80] was 0.824. For FIBTEM MCF and A10 Schöchl et al. [36] demonstrated a AUC of was 0.84 and 0.83 , respectively.

Furthermore, in our study, EXTEM and INTEM MCF were found to be independent predictors for platelet transfusion with an AUC of 0.73 and 0.82 , respectively, and for cryoprecipitate the respective values were AUC of 0.78 and 0.8 . This is in agreement with Roullet et al. [81] who demonstrated that EXTEM A10 showed a good correlation to platelet count and plasma fibrinogen levels. The predictable threshold for thrombocytopenia $(<50,000$ $\mathrm{mm}^{-3}$ ) was reported as an EXTEM A $10<29 \mathrm{~mm}$ and had a sensitivity and specificity of $79 \%$ and $60 \%$, respectively. The threshold for hypofibrinogenemia $(<1 \mathrm{~g} / \mathrm{l})$ was an EXTEM A10 $<26 \mathrm{~mm}$ with a sensitivity and specificity of $83 \%$ and $75 \%$, respectively. Again, Blasi et al. [82] demonstrated that EXTEM MCF correlated at best with platelet count and plasma fibrinogen blood levels $(\mathrm{r}=$ 0.62 and 0.69 , respectively) and that EXTEM A10 was a good linear predictor of EXTEM MCF $\left(\mathrm{r}^{2}=0.93\right)$. The cut-off value that best predicted the transfusion threshold for platelets was EXTEM A10 = $35 \mathrm{~mm}$. The good linear prediction of EXTEM MCF by EXTEM A5 and A10 ( $r=0.93$ and 0.96 , respectively) was confirmed in 3,939 EXTEM analyses in non-cardiac patients by Görlinger et al. [34]. Accordingly, Song et al. [38] showed in 239 living donor liver transplantations including 1,139 EXTEM analyses, that EXTEM A5 values were highly correlated with EXTEM MCF, platelet count and fibrinogen concentration ( $\mathrm{r}=0.96,0.76$ and 0.63 , respectively). Here, an EXTEM A5 threshold of 15 and $19 \mathrm{~mm}$ predicted a platelet count $<30,000 \mathrm{~mm}^{-3}(\mathrm{AUC}=0.90)$ and $<50,000 \mathrm{~mm}^{-3}(\mathrm{AUC}=$ $0.87)$, respectively.

Olde Engberink et al. [39] reported the same good correlation in patients undergoing cardiac surgery. Here again, EXTEM A5 showed an excellent correlation with EXTEM A10 and MCF ( $\mathrm{r}=$ 0.99 and 0.97 , respectively). The correlation coefficient $r$ for the correlation between EXTEM A5, A10 and MCF and platelet count was $0.74,0.73$ and 0.70 , respectively. Notably, EXTEM A10 and MCF have recently been shown to be superior in predicting bleeding in patients with severe immune thrombocytopenia $(<60,000$ $\mathrm{mm}^{-3}$ ) compared to platelet count. Accordingly, Tripodi et al. [84] demonstrated that the effect of platelet transfusion in patients with cirrhosis can be assessed by thromboelastometry, and unnecessary and potentially harmful platelet transfusion can be avoided [85, 86].

In our study, CT and CFT, which are mainly related to the activity of enzymatic coagulation factors and fibrinogen concentration, were found to be independent predictors for PRBC, FFP, and cryoprecipitate transfusion. This is in agreement with the results published by Plotkin et al. [78] and Leemann et al. [80] who found prolonged CFT in trauma patients with the need for massive transfusion.

Furthermore, we found FIBTEM MCF as an independent predictor for FFP and cryoprecipitate transfusion. Blasi et al. [82] re- 
ported FIBTEM MCF and A10 to correlate with plasma fibrinogen levels $(r=0.70)$; the cut-off value that best predicted the transfusion threshold for fibrinogen was FIBTEM A10 $=8 \mathrm{~mm}$. In addition, Ogawa et al. [87] demonstrated that FIBTEM MCF had an excellent correlation with the plasma fibrinogen level $(r=0.85)$. Rugeri et al. [88] confirmed a strong correlation between FIBTEM A10 and plasma fibrinogen levels in trauma patients $(r=0.85)$. Accordingly, Roullet et al. [81] demonstrated a significant correlation between FIBTEM A10 and the plasma fibrinogen level during liver transplantation $(\mathrm{r}=0.74)$. These results have been confirmed by Song et al. [38] showing in 239 patients undergoing living donor liver transplantation, including 1,125 FIBTEM analyses, that FIBTEM A5 values were highly correlated with FIBTEM A10 and MCF ( $r=0.96$ and 0.95 , respectively) and with fibrinogen concentration $(\mathrm{r}=0.63)$. Here, a FIBTEM A5 threshold $\leq 4 \mathrm{~mm}$ predicted a fibrinogen concentration $<1 \mathrm{~g} / \mathrm{l}$. Similar good correlations between FIBTEM A5 and FIBTEM A10 $(r=0.95)$ or MCF $(r=0.96)$ have been reported by Görlinger et al. [37] based on 3,287 FIBTEM analyses in patients undergoing noncardiac surgery. Recently, Olde Engberink et al. [39] confirmed this excellent correlation between FIBTEM A5 and FIBTEM A10 $(r=1.0)$ and MCF $(r=0.99)$. The correlation coefficient $r$ for the correlation between FIBTEM A5, $\mathrm{A} 10$ or MCF and fibrinogen concentration was $\mathrm{r}=0.97,0.86$ or 0.87 , respectively. Accordingly, the FIBTEM clot firmness parameters MCF, A10 and A5 seem to be good variables to predict transfusion requirement for fibrinogen-rich blood components including fibrinogen concentrate, cryoprecipitate, and FFP as found in our study. These results are also supported by the study published by Rumph et al. [89].

The assigned variables in the regression equations were all expected to increase or decrease transfusion requirements as it is well known that high MCF and angle $\alpha$ and low CT and CFT have protective effects against transfusion of different blood products and vice versa. What actually these equations add is to provide an idea about the weight of each factor in preventing or increasing the likelihood to transfusion also the incorporation of all these factors together which may help prediction of blood products requirements. Since coagulopathy in cirrhosis is multifactorial, a regression equation, including multiple thromboelastometric variables, seems to be more adequate than prediction of bleeding and transfusion requirements based on one variable only.

One limitation of this study is that thromboelastometry cannot assess von Willebrand factor and vascular wall disorders as well as platelet and endothelial cell dysfunction [23, 25, 46-51]. Of course, these factors have to be considered in case of microvascular bleeding, too. Furthermore, transfusion requirements can be affected by further intraoperative derangement of hemostasis which cannot be reflected by preoperative thromboelastometric analysis. In addition, $\mathrm{PRBC}$ transfusion requirements can be affected by the preoperative hemoglobin level, a parameter which - if considered in re- gression equation - can improve its predictive power. Furthermore, this predictive model cannot consider blood loss and transfusion requirements due to surgical bleeding which might be aggravated by volume overload and portal hypertension [7, 22, 29, 45]. Finally, a change in the thromboelastometry-guided bleeding management algorithm - e.g. by using coagulation factor concentrates instead of allogeneic blood products - might change transfusion requirements in patients undergoing liver transplantation [4, 23, 41-46]. Therefore, this predictive model has to be re-validated in other liver transplant patient populations using the same and different thromboelastometry-guided bleeding management algorithms [90].

In conclusion, preoperative thromboelastometric analysis seems to be a good predictor of transfusion requirement in recipients of ALDLT. Here, thromboelastometry was most valuable in predicting FFP transfusion requirements. Furthermore, MCF was an independent predictor for PRBC, cryoprecipitate, and platelet transfusion, while CT and CFT were independent predictors of PRBC, cryoprecipitate, and FFP transfusion. This may allow for better preparation and less cross-matching prior to surgery. However, the findings our study have to be seen in the context of a patient blood management program and need to be re-validated in other liver transplant centers using the same and different thromboelastometry-guided bleeding management algorithms.

\section{Attribution of the Work}

Nirmeen Fayed designed the study, collected and co-analyzed the data, and authored the manuscript. She has seen the original study data, reviewed the analysis of the data, and approved the final manuscript.

Wessam Mourad co-designed the study, analyzed the data and co-authored the manuscript. She has seen the original study data, reviewed the analysis of the data, and approved the final manuscript.

Khaled Yassen co-designed the study, co-analyzed the data and co-authored the manuscript. He has seen the original study data, reviewed the analysis of the data, and approved the final manuscript.

Klaus Görlinger co-designed the study, co-analyzed the data, and co-authored the manuscript. He has seen the original study data, reviewed the analysis of the data, and approved the final manuscript.

\section{Financial Support}

Departmental sources only.

\section{Disclosure Statement}

Klaus Görlinger works as the medical director of Tem International GmbH, Munich, Germany since July 2012. Nirmeen Fayed, Wessam Mourad and Khaled Yassen declare that they have no conflicts of interest relevant to the manuscript. 


\section{References}

1 Ozier Y, Pessione F, Samain E, Courtois F: Institutional variability in transfusion practice for liver transplantation. Anesth Analg 2003;97:671-679.

2 Sakai T, Matsusaki T, Dai F, Tanaka KA, Donaldson JB, Hilmi IA, Wallis Marsh J, Planinsic RM, Humar A Pulmonary thromboembolism during adult liver transplantation: incidence, clinical presentation, outcome, risk factors, and diagnostic predictors. Br J Anaesth 2012;108:469-477.

3 Schumann R1, Mandell MS, Mercaldo N, Michaels D, Robertson A, Banerjee A, Pai R, Klinck J, Pandharipande P, Walia A: Anesthesia for liver transplantation in United States academic centers: intraoperative practice. J Clin Anesth 2013;25:542-550.

4 Kirchner C, Dirkmann D, Treckmann JW, Paul A Hartmann M, Saner FH, Görlinger K: Coagulation management with factor concentrates in liver transplantation: a single-center experience. Transfusion 2014;54:2760-2768.

5 Tripodi A, Primignani M, Chantarangkul V, Viscardi Y, Dell'Era A, Fabris FM, Mannucci PM: The coagulopathy of cirrhosis assessed by thromboelastometry and its correlation with conventional coagulation parameters. Thromb Res 2009;124:132-136.

6 Schaden E, Saner FH, Goerlinger K: Coagulation pattern in critical liver dysfunction. Curr Opin Crit Care 2013;19:142-148.

7 Saner FH, Gieseler RK, Akız H, Canbay A, Görlinger $\mathrm{K}$ : Delicate balance of bleeding and thrombosis in endstage liver disease and liver transplantation. Digestion 2013;88:135-144.

8 Ozier YM, Le Cam B, Chatellier G, Eyraud D, Soubrane O, Houssin D, Conseiller C: Intraoperative blood loss in pediatric liver transplantation: analysis of preoperative risk factors. Anesth Analg 1995;81:1142-1147.

-9 Massicotte L, Beaulieu D, Roy JD, Marleau D, Vandenbroucke F, Dagenais M, Lapointe R, Roy A: MELD score and blood product requirements during liver transplantation: no link. Transplantation 2009;87: 1689-1694.

10 Cywinski JB, Alster JM, Miller C, Vogt DP, Parker BM Prediction of intraoperative transfusion requirements during orthotopic liver transplantation and the influence on postoperative patient survival. Anesth Analg 2014;118:428-437.

11 Blake J, Nemergut EC: Hope for the best, but prepare for the worst. Anesth Analg 2014;118:249-250.

-12 Dalmau A Sabaté A, Acosta F, Garcia-Huete L, Koo M, Sansano T, Rafecas A, Figueras J, Jaurrieta E, Parrilla P: Tranexamic acid reduces red cell transfusion better than epsilon-aminocaproic acid or placebo in liver transplantation. Anesth Analg 2000;91:29-34.

13 Porte RJ, Molenaar IQ, Begliomini B, Groenland TH, Januszkiewicz A, Lindgren L, Palareti G, Hermans J, Terpstra OT: Aprotinin and transfusion requirements in orthotopic liver transplantation: a multicentre randomised double-blind study. EMSALT study group. Lancet 2000;355:1303-1309.

14 Rando K, Niemann CU, Taura P, Klinck J: Optimizing cost-effectiveness in perioperative care for liver transplantation: a model for low- to medium-income countries. Liver Transpl 2011;17:1247-1278.

15 Görlinger K, Schlenke P: Patient Blood Management: Clinical hemotherapy and hemostasis management in perioperative settings. Transfus Med Hemother 2012; 39:57-58.

16 Clevenger B, Mallett SV: Transfusion and coagulation management in liver transplantation. World J Gastroenterol 2014;20:6146-6158.

17 Shander A, Hofmann A, Ozawa S, Theusinger OM, Gombotz H, Spahn DR: Activity-based costs of blood transfusions in surgical patients at four hospitals. Transfusion 2010;50:753-765.
Hofmann A, Ozawa S, Farrugia A, Farmer SL, Shander A: Economic considerations on transfusion medicine and patient blood management. Best Pract Res Clin Anaesthesiol 2013;27:59-68.

19 Görlinger K, Kozek-Langenecker SA: Economic aspects and organization; in Marcucci CE, Schoettker P (eds): Perioperative Hemostasis - Coagulation for Anesthesiologists. Heidelberg, Springer, 2015, pp 421-445.

20 Steib A, Gengenwin N, Freys G, Boudjema K, Levy S, Otteni JC: Predictive factors of hyperfibrinolytic activity during liver transplantation in cirrhotic patients. Br J Anaesth 1994;73:645-648.

21 Gerlach H, Gossé F, Rossaint R, Bechstein WO, Neuhaus $\mathrm{P}$, Falke KJ: The relevance of perioperative coagulation parameters to indications for blood transfusion. A retrospective analysis of 300 liver transplantations. Anaesthesist 1994;43:168-177.

22 de Boer MT, Molenaar IQ, Hendriks HG, Slooff MJ, Porte RJ: Minimizing blood loss in liver transplantation: progress through research and evolution of techniques. Dig Surg 2005;22:265-275.

23 Görlinger K, Schaden E, Saner FH: Perioperative hemostasis in hepatic surgery; in Marcucci CE, Schoettker P (eds): Perioperative Hemostasis - Coagulation for Anesthesiologists. Heidelberg, Springer, 2015, pp 267-283.

24 Society of Thoracic Surgeons Blood Conservation Guideline Task Force, Ferraris VA, Brown JR, Despotis GJ, Hammon JW, Reece TB, Saha SP, Song HK, Clough ER; Society of Cardiovascular Anesthesiologists Special Task Force on Blood Transfusion, Shore-Lesserson LJ, Goodnough LT, Mazer CD, Shander A, Stafford-Smith M, Waters J; International Consortium for Evidence Based Perfusion, Baker RA, Dickinson TA, FitzGerald DJ, Likosky DS, Shann KG: 2011 update to the Society of Thoracic Surgeons and the Society of Cardiovascular Anesthesiologists blood conservation clinical practice guidelines. Ann Thorac Surg 2011;91:944-982.

25 Kozek-Langenecker SA, Afshari A, Albaladejo P, Santullano CA, De Robertis E, Filipescu DC, Fries D, Görlinger K, Haas T, Imberger G, Jacob M, Lancé M, Llau J, Mallett S, Meier J, Rahe-Meyer N, Samama CM, Smith A, Solomon C, Van der Linden P, Wikkelsø AJ, Wouters P, Wyffels P: Management of severe perioperative bleeding: guidelines from the European Society of Anaesthesiology. Eur J Anaesthesiol 2013;30:270-382.

26 Ewe K: Bleeding after liver biopsy does not correlate with indices of peripheral coagulation. Dig Dis Sci 1981;26:388-393.

27 Kozek-Langenecker S: Management of massive operative blood loss. Minerva Anestesiol 2007;73:401-415

28 Tripodi A, Caldwell SH, Hoffman M, Trotter JF, Sanyal AJ: Review article: the prothrombin time test as a measure of bleeding risk and prognosis in liver disease. Aliment Pharmacol Ther 2007;26:141-148.

29 Massicotte L, Beaulieu D, Thibeault L, Roy JD, Marleau D, Lapointe R, Roy A: Coagulation defects do not predict blood product requirements during liver transplantation. Transplantation 2008;85:956-962.

30 Toulon P, Ozier Y, Ankri A, Fléron MH, Leroux G, Samama CM: Point-of-care versus central laboratory coagulation testing during haemorrhagic surgery. A multicenter study. Thromb Haemost 2009;101:394-401.

31 Tripodi A, Mannucci PM: The coagulopathy of chronic liver disease. N Engl J Med 2011;365:147-155.

32 Townsend JC, Heard R, Powers ER, Reuben A: Usefulness of international normalized ratio to predict bleeding complications in patients with end-stage liver disease who undergo cardiac catheterization. Am J Cardiol 2012;110:1062-1065.
3 Haas T, Spielmann N, Mauch J, Madjdpour C, Speer $\mathrm{O}$, Schmugge M, Weiss M: Comparison of thromboelastometry $\left(\right.$ ROTEM $\left.^{\circledR}\right)$ with standard plasmatic coagulation testing in paediatric surgery. Br J Anaesth 2012;108:36-41.

34 Haas T, Spielmann N, Mauch J, Speer O, Schmugge M, Weiss M: Reproducibility of thrombelastometry $\left(\right.$ ROTEM $\left.^{\circledR}\right)$ : point-of-care versus hospital laboratory performance. Scand J Clin Lab Invest 2012;72:313-317.

35 Davenport R, Manson J, De'Ath H, Platton S, Coates A, Allard S, Hart D, Pearse R, Pasi KJ, MacCallum P, Stanworth S, Brohi K: Functional definition and characterization of acute traumatic coagulopathy. Crit Care Med 2011;39:2652-2658.

36 Schöchl H, Cotton B, Inaba K, Nienaber U, Fischer H, Voelckel W, Solomon C: FIBTEM provides early prediction of massive transfusion in trauma. Crit Care 2011,15:R265.

37 Görlinger K, Dirkmann D, Solomon C, Hanke AA: Fast interpretation of thromboelastometry in non-cardiac surgery: reliability in patients with hypo-, normo-, and hypercoagulability. Br J Anaesth 2013;110:222-230.

38 Song JG, Jeong SM, Jun IG, Lee HM, Hwang GS: Five-minute parameter of thromboelastometry is sufficient to detect thrombocytopenia and hypofibrinogenaemia in patients undergoing liver transplantation. Br J Anaesth 2014;112:290-297.

39 Olde Engberink RH, Kuiper GJ, Wetzels RJ, Nelemans PJ, Lance MD, Beckers EA, Henskens YM: Rapid and correct prediction of thrombocytopenia and hypofibrinogenemia with rotational thromboelastometry in cardiac surgery. J Cardiothorac Vasc Anesth 2014;28: 210-216.

40 Hoffman M, Monroe DM 3rd: A cell-based model of hemostasis. Thromb Haemost 2001;85:958-965.

41 Görlinger K, Dirkmann D, Müller-Beißenhirtz H, Paul A, Hartmann M, Saner F: Thromboelastometry-based perioperative coagulation management in visceral surgery and liver transplantation: experience of 10 years and 1105 LTX. Liver Transplant 2010;16(suppl 1):S86.

42 Trzebicki J, Flakiewicz E, Kosieradzki M, Blaszczyk B, Kołacz M, Jureczko L, Pacholczyk M, Chmura A, Lagiewska B, Lisik W, Wasiak D, Kosson D, Kwiatkowski A, Lazowski T: The use of thromboelastometry in the assessment of hemostasis during orthotopic liver transplantation reduces the demand for blood products. Ann Transplant. 2010;15:19-24.

43 Görlinger K, Fries D, Dirkmann D, Weber CF, Hanke AA, Schöchl H: Reduction of fresh frozen plasma requirements by perioperative point-of-care coagulation management with early calculated goal-directed therapy. Transfus Med Hemother 2012;39:104-113.

44 Tanaka KA, Bader SO, Görlinger K: Novel approaches in management of perioperative coagulopathy. Curr Opin Anaesthesiol 2014;27:72-80.

45 Haas T, Görlinger K, Grassetto A, Agostini V, Simioni P, Nardi G, Ranucci M: Thromboelastometry for guiding bleeding management of the critically ill patient: a systematic review of the literature. Minerva Anestesiol 2014;80:1320-1335.

46 Luddington RJ: Thromboelastography/thromboelastometry. Clin Lab Haematol 2005;27:81-90.

47 Görlinger K: Coagulation management during liver transplantation. Hämostaseologie 2006;26(suppl 1): S64-76.

48 Görlinger K, Jambor C, Hanke AA, Dirkmann D, Adamzik M, Hartmann M, Rahe-Meyer N: Perioperative coagulation management and control of platelet transfusion by point-of-care platelet function analysis. Transfus Med Hemother 2007;34:396-411. 
49 Larsen OH, Fenger-Eriksen C, Christiansen K, Ingerslev J, Sørensen B: Diagnostic performance and therapeutic consequence of thromboelastometry activated by kaolin versus a panel of specific reagents. Anesthesiology 2011;115:294-302.

50 Whiting D, DiNardo JA: TEG and ROTEM: technology and clinical applications. Am J Hematol 2014;89: 228-232.

51 Tanaka KA, Bader SO, Sturgil EL: Diagnosis of perioperative coagulopathy - plasma versus whole blood testing. J Cardiothorac Vasc Anesth 2013;27(4 suppl): S9-15.

52 Lier H, Vorweg M, Hanke A, Görlinger K: Thromboelastometry guided therapy of severe bleeding. Essener Runde algorithm. Hämostaseologie 2013;33:51-61.

53 Schöchl H, Maegele M, Solomon C, Görlinger K, Voelckel W: Early and individualized goal-directed therapy for trauma-induced coagulopathy. Scand J Trauma Resusc Emerg Med 2012;20:15.

54 Da Luz LT, Nascimento B, Shankarakutty AK, Rizoli S, Adhikari NK: Effect of thromboelastography $\left(\mathrm{TEG}^{\circledR}\right)$ and rotational thromboelastometry $\left(\right.$ ROTEM $\left.^{\circledR}\right)$ on diagnosis of coagulopathy, transfusion guidance and mortality in trauma: descriptive systematic review. Crit Care 2014 27; 18:518.

55 Coakley M, Reddy K, Mackie I, Mallett S: Transfusion triggers in orthotopic liver transplantation: a comparison of the thromboelastometry analyzer, the thromboelastogram, and conventional coagulation tests. J Cardiothorac Vasc Anesth 2006;20:548-553.

56 Mallett SV, Chowdary P, Burroughs AK: Clinical utility of viscoelastic tests of coagulation in patients with liver disease. Liver Int 2013;33:961-974.

57 Görlinger K, Dirkmann D, Hanke AA, Kamler M, Kottenberg E, Thielmann M, Jakob H, Peters J: First-line therapy with coagulation factor concentrates combined with point-of-care coagulation testing is associated with decreased allogeneic blood transfusion in cardiovascular surgery: a retrospective, single-center cohort study. Anesthesiology 2011;115:1179-1191.

58 Weber CF, Görlinger K, Meininger D, Herrmann E, Bingold T, Moritz A, Cohn LH, Zacharowski K: Pointof-care testing: a prospective, randomized clinical trial of efficacy in coagulopathic cardiac surgery patients. Anesthesiology 2012;117:531-547.

59 Görlinger K, Dirkmann D, Hanke AA: Potential value of transfusion protocols in cardiac surgery. Curr Opin Anaesthesiol 2013;26:230-243.

60 Karkouti K, McCluskey SA, Callum J, Freedman J, Selby R, Timoumi T, Roy D, Rao V: Evaluation of a novel transfusion algorithm employing point-of-care coagulation assays in cardiac surgery: a retrospective cohort study with interrupted time-series analysis. Anesthesiology 2015;122:560-570.

61 Nakayama Y, Nakajima Y, Tanaka KA, Sessler DI, Maeda S, Iida J, Ogawa S, Mizobe T: Thromboelastometry-guided intraoperative haemostatic management reduces bleeding and red cell transfusion after paediatric cardiac surgery. Br J Anaesth 2015;114:91-102.

62 Gross JB: Estimating allowable blood loss: corrected for dilution. Anesthesiology 1983;58:277-280.

63 Caldwell SH, Hoffman M, Lisman T, Macik BG, Northup PG, Reddy KR, Tripodi A, Sanyal AJ; Coagulation in Liver Disease Group: Coagulation disorders and hemostasis in liver disease: pathophysiology and critical assessment of current management. Hepatology 2006; 44:1039-1046.
64 Shah NL, Intagliata NM, Northup PG, Argo CK, Caldwell SH: Procoagulant therapeutics in liver disease: a critique and clinical rationale. Nat Rev Gastroenterol Hepatol 2014;11:675-682.

65 Haas T, Fries D, Tanaka KA, Asmis L, Curry NS, Schöchl H: Usefulness of standard plasma coagulation tests in the management of perioperative coagulopathic bleeding: is there any evidence? Br J Anaesth 2015; 114:217-224

66 DeLoughery TG, Liebler JM, Simonds V, Goodnight SH: Invasive line placement in critically ill patients: do hemostatic defects matter? Transfusion 1996;36:827831.

67 Fisher NC, Mutimer DJ: Central venous cannulation in patients with liver disease and coagulopathy - a prospective audit. Intensive Care Med 1999;25:481-485.

68 McVay PA, Toy PT: Lack of increased bleeding after liver biopsy in patients with mild hemostatic abnormalities. Am J Clin Pathol 1990;94:747-753.

69 Segal JB, Dzik WH: Paucity of studies to support that abnormal coagulation test results predict bleeding in the setting of invasive procedures: an evidence-based review. Transfusion 2005;45:1413-1425.

$70 \mathrm{Ng}$ KF, Lai KW, Tsang SF: Value of preoperative coagulation tests: reappraisal of major noncardiac surgery. World J Surg 2002;26:515-520.

71 Eckman MH, Erban JK, Singh SK, Kao GS: Screening for the risk for bleeding or thrombosis. Ann Intern Med 2003;138:W15-24.

72 Reyle-Hahn M, Rossaint R: Coagulation techniques are not important in directing blood product transfusion during liver transplantation. Liver Transpl Surg 1997; 3:659-665.

73 Ronald A, Dunning J: Can the use of thromboelastography predict and decrease bleeding and blood product requirements in adult patients undergoing cardiac surgery? Interact Cardiovasc Thorac Surg 2005;4: 456-463.

74 Davidson SJ, McGrowder D, Roughton M, Kelleher AA: Can ROTEM thromboelastometry predict postoperative bleeding after cardiac surgery? J Cardiothorac Vasc Anesth 2008;22:655-661.

75 Cammerer U, Dietrich W, Rampf T, Braun SL, Richter JA: The predictive value of modified computerized thromboelastography and platelet function analysis for postoperative blood loss in routine cardiac surgery. Anesth Analg 2003;96:51-57.

76 Lee GC, Kicza AM, Liu KY, Nyman CB, Kaufman RM, Body SC: Does rotational thromboelastometry (ROTEM) improve prediction of bleeding after cardiac surgery? Anesth Analg 2012;115:499-506.

77 Reinhöfer M, Brauer M, Franke U, Barz D, Marx G, Lösche W: The value of rotation thromboelastometry to monitor disturbed perioperative haemostasis and bleeding risk in patients with cardiopulmonary bypass. Blood Coagul Fibrinolysis 2008;19:212-219.

78 Plotkin AJ, Wade CE, Jenkins DH, Smith KA, Noe JC, Park MS, Perkins JG, Holcomb JB: A reduction in clot formation rate and strength assessed by thrombelastography is indicative of transfusion requirements in patients with penetrating injuries. J Trauma 2008;64(2 suppl):S64-68.
Jeger V, Willi S, Liu T, Yeh DD, De Moya M, Zimmermann H, Exadaktylos AK: The Rapid TEG $a$-angle may be a sensitive predictor of transfusion in moderately injured blunt trauma patients. Sci World J 2012; 2012:821794.

80 Leemann H, Lustenberger T, Talving P, Kobayashi L, Bukur M, Brenni M, Brüesch M, Spahn DR, Keel MJ: The role of rotation thromboelastometry in early prediction of massive transfusion. J Trauma 2010;69: 1403-1409.

81 Roullet S, Pillot J, Freyburger G, Biais M, Quinart A, Rault A, Revel P, Sztark F: Rotation thromboelastometry detects thrombocytopenia and hypofibrinogenaemia during orthotopic liver transplantation. $\mathrm{Br}$ J Anaesth 2010;104:422-428.

82 Blasi A, Beltran J, Pereira A, Martinez-Palli G, Torrents A, Balust J, Zavala E, Taura P, Garcia-Valdecasas JC: An assessment of thromboelastometry to monitor blood coagulation and guide transfusion support in liver transplantation. Transfusion 2012;52:1989-1998.

83 Greene LA, Chen S, Seery C, Imahiyerobo AM, Bussel JB: Beyond the platelet count: immature platelet fraction and thromboelastometry correlate with bleeding in patients with immune thrombocytopenia. $\mathrm{Br} \mathrm{J} \mathrm{Hae}-$ matol 2014;166:592-600.

84 Tripodi A, Primignani M, Chantarangkul V, Lemma L, Jovani M, Rebulla P, Mannucci PM: Global hemostasis tests in patients with cirrhosis before and after prophylactic platelet transfusion. Liver Int 2013;33:362367

85 Fayed NA, Abdallah AR, Khalil MK, Marwan IK: Therapeutic rather than prophylactic platelet transfusion policy for severe thrombocytopenia during liver transplantation. Platelets 2014;25:576-586.

86 Pereboom IT, de Boer MT, Haagsma EB, Hendriks HG, Lisman T, Porte RJ: Platelet transfusion during liver transplantation is associated with increased postoperative mortality due to acute lung injury. Anesth Analg 2009;108:1083-1091.

87 Ogawa S, Szlam F, Chen EP, Nishimura T, Kim H, Roback JD, Levy JH, Tanaka KA: A comparative evaluation of rotation thromboelastometry and standard coagulation tests in hemodilution-induced coagulation changes after cardiac surgery. Transfusion 2012;52: $14-22$.

88 Rugeri L, Levrat A, David JS, Delecroix E, Floccard B, Gros A, Allaouchiche B, Negrier C: Diagnosis of early coagulation abnormalities in trauma patients by rotation thrombelastography. J Thromb Haemost 2007;5: 289-295.

89 Rumph B, Bolliger D, Narang N, Molinaro RJ, Levy JH, Szlam F, Tanaka KA: In vitro comparative study of hemostatic components in warfarin-treated and fibrinogen-deficient plasma. J Cardiothorac Vasc Anesth 2010;24:408-412.

90 Maegele M, Lefering R, Wafaisade A, Theodorou P, Wutzler S, Fischer P, Bouillon B, Paffrath T; Trauma Registry of Deutsche Gesellschaft für Unfallchirurgie (TR-DGU): Revalidation and update of the TASHScore: a scoring system to predict the probability for massive transfusion as a surrogate for life-threatening haemorrhage after severe injury. Vox Sang 2011;100: 231-238. 